\title{
Model of optical response of marine aerosols to Forbush decreases
}

\author{
T. Bondo, M. B. Enghoff, and H. Svensmark \\ National Space Institute, Technical University of Denmark, Copenhagen, Denmark \\ Received: 18 August 2009 - Published in Atmos. Chem. Phys. Discuss.: 27 October 2009 \\ Revised: 21 January 2010 - Accepted: 20 March 2010 - Published: 24 March 2010
}

\begin{abstract}
In order to elucidate the effect of galactic cosmic rays on cloud formation, we investigate the optical response of marine aerosols to Forbush decreases - abrupt decreases in galactic cosmic rays - by means of modeling. We vary the nucleation rate of new aerosols, in a sectional coagulation and condensation model, according to changes in ionization by the Forbush decrease. From the resulting size distribution we then calculate the aerosol optical thickness and Angstrom exponent, for the wavelength pairs $350,450 \mathrm{~nm}$ and $550,900 \mathrm{~nm}$. In the cases where the output parameters from the model seem to compare best with atmospheric observations we observe, for the shorter wavelength pair, a change in Angstrom exponent, following the Forbush Decrease, of -6 to $+3 \%$. In some cases we also observe a delay in the change of Angstrom exponent, compared to the maximum of the Forbush decrease, which is caused by different sensitivities of the probing wavelengths to changes in aerosol number concentration and size. For the long wavelengths these changes are generally smaller. The types and magnitude of change is investigated for a suite of nucleation rates, condensable gas production rates, and aerosol loss rates. Furthermore we compare the model output with observations of 5 of the largest Forbush decreases after year 2000. For the $350,450 \mathrm{~nm}$ pair we use AERONET data and find a comparable change in signal while the Angstrom Exponent is lower in the model than in the data, due to AERONET being mainly sampled over land. For 550, $900 \mathrm{~nm}$ we compare with both AERONET and MODIS and find little to no response in both model and observations. In summary our study shows that the optical properties of aerosols show a distinct response to Forbush Decreases, assuming that the nucleation of fresh aerosols is driven by ions. Shorter wavelengths seem more favorable for observing these effects and great care should be taken when analyzing observations, in order to avoid the signal being drowned out by noise.
\end{abstract}

Correspondence to: $\mathrm{T}$. Bondo (tb@space.dtu.dk)

\section{Introduction}

A Forbush Decrease (FD) is a sudden drop in the amount of galactic cosmic rays observed on Earth, due to large Coronal Mass Ejections from the sun (Forbush, 1937; Cane, 2000). The largest of these events cause up to $10-25 \%$ changes in the cosmic ray count rate but occur rarely - only about once a year - and typically last from a few days to about a week. A correlation between galactic cosmic rays (controlled by solar activity) and cloud cover has been shown (Marsh and Svensmark, 2003; Harrison and Stephenson, 2006). If this correlation is due to a physical mechanism a response in cloud cover could be expected during or after a Forbush decrease. An investigation of a connection between clouds and cosmic rays on a FD time scale would also be able to narrow down the number of potential explanations for the cloud cosmic ray connection as no solar parameters (such as total solar irradiance) correlate well with FD Neutron Monitor counts during the span of a Forbush decrease. FD effects in cloud data have been investigated previously (Pudovkin and Veretenenko, 1995; Kniveton, 2004; Todd and Kniveton, 2004; Harrison and Stephenson, 2006; Kristjánsson et al., 2008; Sloan and Wolfendale, 2008; Svensmark et al., 2009) but no definitive conclusion has been reached. Pudovkin and Veretenenko (1995) investigated 65 Forbush decreases from 1969 to 1986 over four latitudinal bands in Russia and found a significant response in cloud cover in the $60-64^{\circ}$ band. Todd and Kniveton (2004) found a decrease in high cloud cover over Antarctica, using ISCCP D1 data from 1983 to 2000. They conclude that their result could just as well be due to the uncertainties in polar cloud retrieval as it could be a real signal. Correlations at $20-30^{\circ} \mathrm{N}$ and $10-20^{\circ} \mathrm{S}$ also appear when the effects of rainfall are removed (Kniveton, 2004). In Harrison and Stephenson (2006), ground level observations of the diffuse fraction of light due to scattering by particles are found to be affected by Forbush decreases in the period 1968 to 1994. In Tinsley (2008) a review is given of a series of papers investigating how electro-freezing and cloud scavenging also may cause a response in cloud

Published by Copernicus Publications on behalf of the European Geosciences Union. 


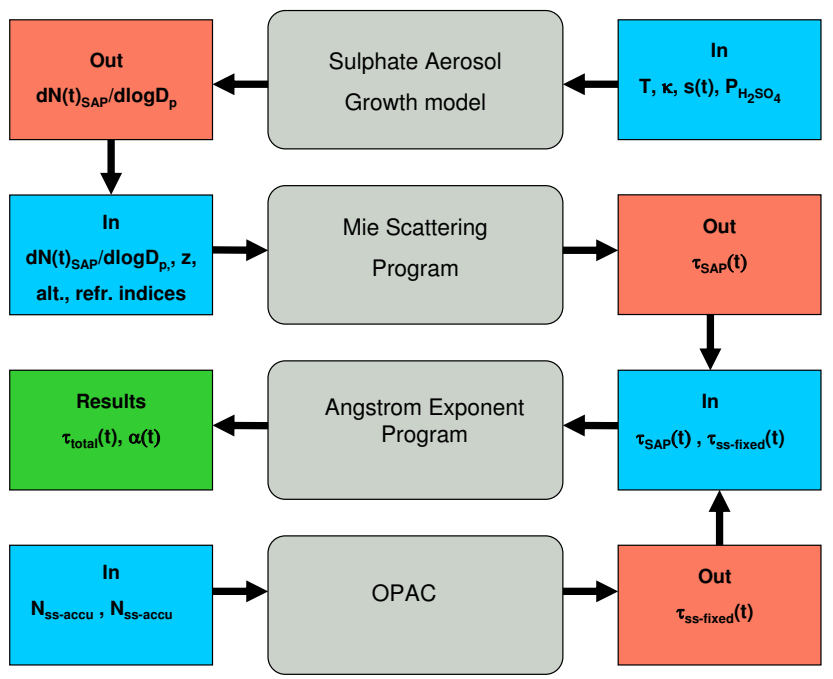

Fig. 1. Flowchart of the theoretical model based on 4 steps. Definitions of input and outputs. See text for more details.

cover to a FD. Kristjánsson et al. (2008) analysed 22 events using MODIS data from pristine Souther Hemisphere ocean regions. Little significant response in cloud parameters was found even though the correlations improved somewhat by focusing on the six strongest events. Sloan and Wolfendale (2008) found no significant response either. This is in contrast to results from Svensmark et al. (2009) where an epoch analysis of three independent data sets was used to show a decrease in liquid water clouds about 10 days after a FD. These results are explained as a decrease in nucleation mode aerosols growing to affect $\mathrm{CCN}$ and cloud cover over a time period similar to the 10 day lag.

Another approach to this issue is to calculate whether it would be plausible to expect a signal at all. Clouds are formed on aerosols and it has been indicated by theory (Arnold, 1980; Laakso et al., 2002; Lovejoy et al., 2004; Yu, 2006), observations (Eichkorn et al., 2002; Lee et al., 2003; Hirsikko et al., 2007; Laakso et al., 2007; Kulmala et al., 2007) and experiments (Kim et al., 1997; Enghoff et al., 2008; Winkler et al., 2008) that ions, formed by cosmic rays, can enhance the formation of these particles. Therefore it can be expected that if a signal in cloud cover, following a Forbush decrease, is to be found, there should also be a signal in the aerosols. It should, however, be noted that a study looking at nucleation events at the SMEAR II station in Finland over a solar cycle did not find any significant connection between cosmic rays and aerosols (Kulmala et al., 2010).

Motivated by the findings in Svensmark et al. (2009) we try to model how such a response would appear in the aerosol optical properties under the assumption that the cluster formation has been modified by the ionization change during the FD. Two parameters are used to describe the optical properties of aerosol populations: Aerosol Optical Thickness
(AOT) and the Angstrom exponent (AE). The AOT is being measured routinely throughout the atmosphere by photometers such as it is being done by AERONET (Holben et al., 1998) - a network of aerosol observations covering most of Earth. It is a measure for how much light penetrates the atmosphere at a given wavelength, such that a higher AOT means that less light gets through. Both particle number concentration and radius affects the AOT thus changes in AOT can be interpreted in various ways. The AE (Schuster et al., 2006; Eck et al., 1999; Reid et al., 1999) is the slope of the line in a $\log ($ AOT $)$ vs $\log (\lambda)$ plot, where $\lambda$ is the wavelength. Since the AOT at a given $\lambda$ is more sensitive to particles that are close to $\lambda$ in size the AE holds information about the size of the observed particle distribution. A major inhibitor to observe FD effects in aerosols is the existing population of primary aerosols, from pollution, dust storms, sea spray etc. These large particles, which are produced regardless of cosmic rays, is a major sink to freshly nucleated particles (Pierce and Adams, 2007) and can potentially drown out any signal in the aerosol distribution from Forbush decreases. Two recent model papers arrive at different conclusions on the probability of formation of $\mathrm{CCN}$ from ultrafine condensation nuclei (Kuang et al., 2009; Pierce and Adams, 2009) which will affect the signal following a FD. This underlines the relevance of further studies on aerosol growth.

We use a basic nucleation and growth model, sensitive to the cosmic ray flux, to simulate the evolution of a particle distribution in marine conditions, during a Forbush event. In order to calculate the optical properties of the particle distribution the growth model is coupled to a Mie Scattering program: Miex (Wolf, 2004). The sea salt optical properties are derived from the optical properties program OPAC (Hess et al., 1998). Finally we compare the modeling results with measurements from AERONET and MODIS (Platnick et al., 2003).

\section{Theoretical model}

We are interested in determining the changes in the optical properties of a cloud-free marine environment consisting of sulphur gases and sea salt during a Forbush decrease. The theoretical approach is based on 4 steps as illustrated in Fig. 1 and outlined below.

- Aerosol growth model: neutral sulphuric acid aerosol growth is simulated in a marine environment where the cluster production is modulated during a FD. In this part three parameters are varied: the gas phase sulphuric acid production rate, the particle loss rate, and the production rate of stable sulphuric acid clusters.

- Miex part: the particle distribution as a function of time is input to a Mie Scattering program (Miex), along with the relevant refractive indices, and used to calculate the extinction coefficients and optical depths. 
- OPAC part: simultaneously, an optical properties program (OPAC) is used to calculate the optical depth of a fixed sea salt distribution representative for the marine troposphere.

- Optical properties: finally, the total optical depth and Angstrom exponent is calculated as a function of time for the combined sea salt distribution and sulphuric acid particles.

\subsection{The aerosol growth model}

The numerical model is based on the general dynamic equation (GDE) which is a partial differential equation for aerosol particle growth (Seinfeld and Pandis, 2006). A sectional method is used to solve the GDE to determine the number distribution $n$, where bins of variable sizes represent different sizes of the molecular clusters expressed as the number of sulphuric acid molecules in the cluster. The sizes of these bins can be chosen arbitrarily but can limit the integration accuracy. In this work the initial clusters are sampled with each bin representing the addition of one sulphuric acid molecule up to 70 molecules (approx. $3.5 \mathrm{~nm}$ ) followed by a slowly increasing bin size to around 450 molecules and then the bin size is increased with a factor of 1.1 per bin.

Adopting equivalent notation to that of (Lovejoy et al., 2004) the discrete partial derivative of the neutral sulfuric acid cluster distribution function for bin $i, n(i)$ is given by:

$$
\begin{aligned}
& \frac{\partial n(i)}{\partial t}= \\
& \frac{k_{i-1}^{c}\left[\mathrm{H}_{2} \mathrm{SO}_{4}\right] n(i-1)}{\left(n c_{i}-n c_{i-2}\right) / 2 .}-\frac{k_{i}^{c}\left[\mathrm{H}_{2} \mathrm{SO}_{4}\right] n(i)}{\left(n c_{i+1}-n c_{i-1}\right) / 2 .}+ \\
& 0.5 \sum_{l} \sum_{j} k_{j, l}^{e} n(j) n(l) \frac{\left(n c_{l}+n c_{j}\right)-n c_{i-1}}{\left(n c_{i}-n c_{i-1}\right)} \delta_{\left(n_{l}+n_{j}\right),\left[n c_{i-1}, n c_{i}\right]}+ \\
& 0.5 \sum_{l} \sum_{j} k_{j, l}^{e} n(j) n(l) \frac{n c_{i+1}-\left(n c_{l}+n c_{j}\right)}{\left(n c_{i+1}-n c_{i}\right)} \delta_{\left(n_{l}+n_{j}\right),\left[n c_{i+1}, n c_{i}\right]}- \\
& \lambda_{\mathrm{par}} n(i)-n(i) * \sum_{l}\left(k_{i, l}^{e} * n(l)\right)
\end{aligned}
$$

The first term in the first line is the production of $n(i)$ onto the previous bin by condensation of a sulfuric acid molecule. Hence the second term in the first line is the loss in bin i due to creation of a molecule in bin $i+1$. The next two terms represent the coagulation of the individual clusters. Here the delta functions and the fractions take the increasing sizes of the bins into account and make sure to fractionalize the coagulated particles into the correct bins. The sums makes sure that particles of all sizes are accounted for. The second to last term describes various loss processes for the particles and is explained in detail in Sect. 3. The last term is the loss through coagulation.
The condensation coefficients $k_{i}^{c}$ are found according to Laakso et al. (2002) with a value of the mass accommodation coefficient of 1 (Laaksonen et al., 2005). The mean free path used to determine $k_{i}^{c}$ is found from Lehtinen and Kulmala (2003). The cluster diameter as a function of bin size must also be found. This is nontrivial since the mole fraction of sulphuric acid will change with cluster growth. Here it is assumed that an initial sulphuric acid particle is wet and Seinfeld and Pandis (2006, Chap. 10) is used to determine the cluster diameter and mole fraction as a function of number of sulphuric acid molecules. The coagulation coefficients are determined from Laakso et al. (2002). These coefficients can be used for all Knudsen numbers and hence in all growth regimes from diameters of a few angstroms to sizes up to $>1$ microns. The model does not go into the chemistry of the nucleation but assumes that nucleated particles are placed into a predetermined bin at a given rate. This represents stable particle formation by nucleation. The particles are assumed to be 2 molecules big and are thus placed in bin 2 with a cluster formation rate $s$. Within each simulation the production term, $s$, is held constant except for variations due to the Forbush Decreases. In a real atmosphere $s$ would vary due to changes in e.g. sulphuric acid concentration. Since this model describes a simplified situation these variations are not considered in this study.

The rate of change of the sulphuric acid concentration is solved by the following equation :

$$
\frac{d \mathrm{H}_{2} \mathrm{SO}_{4}}{d t}=P_{\mathrm{H}_{2} \mathrm{SO}_{4}}-\left[\mathrm{H}_{2} \mathrm{SO}_{4}\right] \sum_{i} n_{i} \cdot k_{i}^{c}
$$

Here, the first term, $P_{\mathrm{H}_{2} \mathrm{SO}_{4}}$, is the production of gaseous sulphuric acid and the second term the gas losses to the aerosols by condensation. In Enghoff et al. (2008) the aerosol growth within a small chamber with wall losses was modeled. In the present setup there are no wall losses. Instead losses to primary particles are included in the condensation equations. The losses are discussed in Sect. 3. Throughout the simulations the sulphuric acid production term is kept constant. The reason for this is that the simulation is supposed to be a model of an "average" marine environment where there always will be daylight in some part of the box.

\subsection{Miex part}

Miex is a Mie Scattering program originally developed to model interstellar dust scattering (Wolf, 2004). However, the code works equally well on an ensemble of aerosol particles over a large wavelength range providing that the size distribution of the aerosols and their refractive index is known. We have modified the code to calculate the extinction coefficient $\sigma_{\text {ext }}$ from an ensemble of wet sulphuric acid particles (SAP) with relative humidity 0.5 and with a size distribution given by the aerosol growth model. The database of index of refraction for sulphuric acid particles as a function of wavelength is given by Hess et al. (1998). 
Assuming that the concentration of sulphuric acid particles is exponentially decaying with height $(h)$ in the troposphere (extending from $0-10 \mathrm{~km}$ ) the optical thickness for wavelength $\lambda$ can now be calculated from the extinction coefficient:

$\tau_{\mathrm{SAP}}(\lambda)=\sigma_{\mathrm{ext}}(\lambda) N_{\mathrm{SAP}} \int_{H \min }^{H \max } \exp ^{\frac{-h}{Z}} d h$,

where $Z$ is the scale height, $H \min$ is $0 \mathrm{~km}, H \max$ is $10 \mathrm{~km}$ and $N_{\mathrm{SAP}}$ is the concentration of sulphuric acid particles calculated by the aerosol model. Note that we use extinction coefficients, which are normalized to 1 particle $\mathrm{cm}^{-3}$. This assumption implies that aerosols nucleate with the same mixing ratio throughout the troposphere. In reality this is unlikely to be true since particles usually either nucleate above the boundary layer, in the upper troposphere, or within the boundary layer following a rain out of pre-existing particles. Additionally observations do not show this well-mixed behavior (Clarke and Kapustin, 2002). If the nucleation is restricted to specific parts of the troposphere a smaller response could be expected for the FD. On the other hand a rain out would reduce the presence of sea salt which could enhance the signal. This problem could be resolved by introducing layers in the model, but it is not possible within the confines of this box model.

\subsection{OPAC part}

OPAC is software tool designed to calculate optical properties for various atmospheric scenarios including changing cloud cover and aerosol distributions (Hess et al., 1998). The sizes and width of aerosol distributions are changed according to their log-normal distributions. Here, the program is used to calculate extinction coefficients and optical thicknesses $\tau_{\mathrm{SS}}$ for a clean atmosphere with only a marine boundary layer of sea salt particles. The sea salt distribution remains constant throughout each individual run and only serves as a background. The distribution of sea salt particles has both a coarse and accumulation mode given by:

$$
\frac{d N(r)}{d r}=\frac{N}{\sqrt{2 \pi} r \log \sigma \ln 10} \exp \left[-0.5\left(\frac{\log r-\log r_{\text {mod }}}{\log \sigma}\right)^{2}\right] \text {, }
$$

where $\quad \sigma($ coarse/accu $)=[2.03 / 2.03]$ and $r_{\text {mod }}($ coarse $/ \mathrm{accu})=[1.75 / 0.209] \mu \mathrm{m}$ and $N$ coarse/accu $=$ $\left[3.2 \times 10^{-3}, 20\right] \mathrm{cm}^{-3}$, respectively. These two modes are assumed to be generated by a wind speed of $8.9 \mathrm{~m} / \mathrm{s}$ (Hess et al., 1998). As will be described later the contribution from sea salt is varied by systematically changing the concentration of the accumulation and coarse mode.

\subsection{Optical properties}

The time dependent optical thickness for the sulphuric acid particles at different wavelengths is added to the constant optical depth from sea salt and the Angstrom exponent between two wavelengths is calculated as the slope of $\log (\tau)$ vs. $\log$ $\log (\lambda)$ for the two wavelengths:

$\alpha\left(\lambda_{1}, \lambda_{2}, t\right)=-\log \frac{\tau\left(\lambda_{1}, t\right)}{\tau\left(\lambda_{2}, t\right)} / \log \frac{\lambda_{1}}{\lambda_{2}}$,

where $\tau(\lambda, t)=\tau_{\mathrm{SAP}}(t)+\tau_{\mathrm{SS}}$. In this study we focus on the wavelengths $\lambda=350$ and $450 \mathrm{~nm}$. These wavelengths detect $\mathrm{CCN}$ size particles and can be compared to the angstrom exponents as measured by AERONET (Holben et al., 1998). Furthermore the wavelength pair 550 and $900 \mathrm{~nm}$ is used to compare with observations from MODIS (Platnick et al., 2003).

\section{Sensitivity study}

To establish a steady state of background sulphuric acid particles, initially, the sulphuric acid model is run for 7-10 days for various constant cluster formation rates $(s)$, constant sulphuric acid production rates $\left(P_{\mathrm{H}_{2} \mathrm{SO}_{4}}\right)$, and half lives $(\kappa)$ of nucleated particles against primary particles. These runs provide steady state solutions for the aerosol distribution in a parameter space containing values of $s=[0.0001,0.0005$, $0.001, \quad 0.005, \quad 0.01] \mathrm{cm}^{-3} \mathrm{~s}^{-1}, \quad P_{\mathrm{H}_{2} \mathrm{SO}_{4}}=\left[1 \times 10^{3}, 5 \times 10^{3}\right.$, $\left.1 \times 10^{4}, 2 \times 10^{4}\right] \mathrm{cm}^{-3} \mathrm{~s}^{-1}$, and $\kappa=[0.5,1,1.5,2,1000]$ days. The production values of sulphuric acid were chosen such that the sulphuric acid gas concentration reached peak values of about $1 \times 10^{7} \mathrm{~cm}^{-3}$ comparable to the values of Kazil et al. (2006) and Weber et al. (2001). Note that this may be at the high end of the sulphuric acid concentration range. The stable cluster production $s$ is more uncertain. The span of values (two orders of magnitude) represents this uncertainty and is within the range mentioned in Pierce and Adams (2007) and Weber et al. (2001).

In order to estimate the losses of sulphuric acid particles to sea salt and other primary particles the time scale for coagulation losses to the sea salt distribution described in Sect. 2.3 was initially estimated. This was done by running the aerosol growth program with an initial distribution of ultra fine particles and the sea salt distribution described in Sect. 2.3. Omitting condensation, thus only including coagulation, the half time for the losses of the ultrafine particles was estimated to be of the order of half a day. This run represents full mixing between sea salt and sulphuric acid particles and is therefore the upper limit for the coagulation loss of nucleation mode particles to sea salt particles. Under these assumption a range of realistic half-time losses of $\kappa=0.5,1,1.5,2$ days was set and the loss constant for the program determined as $\kappa_{\mathrm{par}}=\ln (2) /(\kappa \times 60)$. A value of $\kappa=1000$ days was also considered as the extreme case where no losses to primary particles are expected. The downside of this approach is that the loss rates has no dependency on particle size. It would have been preferable to include the sea salt explicitly to better describe the particle losses, especially the size dependency. This is an additional reason to include the loss parameter in the sensitivity study. 
An additional loss process for particles is rain. On smaller scales rain is a discrete and abrupt process that basically cleans out an area for particles. Since we consider a sort of average over the ocean we have chosen to incorporate losses to rain into our general loss term $\kappa_{\mathrm{par}}$. General lifetimes for fine particles is days to weeks (Seinfeld and Pandis, 2006, p. 383) which fits well with our choice of loss rates.

The 7-10 day initialization runs provide the starting point for a new run where the cluster production rate, $s$, is modulated by a Forbush decrease. At $t=0$ the Forbush decrease is turned on and the aerosol growth is changed over a period of 36 days with a FD minimum after 15 days. The Forbush decrease profile change in ionization $d Q(t)$ is created by a mean of five major Forbush decreases (31 October 2003, 13 September 2005, 13 June 1991, 19 January 2005, 15 March 1989) from the Climax Neutron monitor including 15 days before and 20 days after the minimum. This gives a profile, $F(t)$, with a $15 \%$ FD decrease minimum (the dashed line in Fig. 3). To create the corresponding relative change in ionization $d Q(t)$ it is assumed that a major Forbush decrease is on the same scale as variations in ionization over the solar cycle, i.e. $\approx 10 \%$ (Usoskin et al., 2004) and $F(t)$ is scaled such that the base level is at zero and the minimum is at $10 \%$ :

$d Q(t)=\left(1 .+0.1 \cdot \frac{F(t)-F(0)}{\max (F(t))-\min (F(t))}\right)$

The aerosol model produces stable clusters at a given unit size. Assuming some form of ion induced nucleation takes place, the production rate, $s$, must depend on the ionization, $Q$. Note that we do not consider the specific mechanism of how $s$ depends on $Q$ but only look at the functional form. This makes the study independent of the exact underlying nucleation mechanism.

Three simple schemes are then possible:

- Square root dependency (standard case)

- Linear Dependency

- Additional nucleation mechanisms occuring simultaneously

\subsection{Square root dependency}

In the standard case $s$ is proportional to the ion concentration, $I$, which in a steady state situation is proportional to the square root of $Q$, due to the following relation:

$\frac{d I}{d t}=Q-C_{\text {rec }} I^{2}$

where $C_{\text {rec }}$ is the coefficient of recombination.

Nucleation experiments by (Svensmark et al., 2007) have also hinted at a square root dependency and for the main part of the paper we will assume this to be the case, such that
Table 1. List of abbreviations.

\begin{tabular}{ll}
\hline AE & Angstrom exponent \\
AERONET & Aerosol Robotics Network (Holben et al., 1998) \\
AOT & Aerosol Optical Thickness \\
FD & Forbush decrease \\
$I$ & Ion concentration \\
ISCCP & International Satellite Cloud Cover Project \\
$\kappa$ & Half life of particles \\
$\kappa$ par & Loss rate of particles \\
$k_{i}^{c}$ & Condensation coefficient \\
$k_{i, j}^{e}$ & Coagulation coefficient \\
$\mathrm{MODIS}_{n}$ & Moderate Resolution Imaging Spectroradiometer \\
$n$ & Particle number concentration \\
$P_{\mathrm{H}_{2} \mathrm{SO}_{4}}$ & Production rate of sulphuric acid \\
$Q$ & Ionisation rate \\
$s$ & Production rate of stable clusters \\
$\mathrm{SAP}$ & Sulphuric Acid Particles \\
$\tau$ & Optical thickness \\
\hline
\end{tabular}

when $Q$ is varied throughout a Forbush decrease, $s$ will follow $d Q$ like:

$s(t)=s_{0} \sqrt{d Q(t)}$

\subsection{Linear dependency}

In the case that larger aerosols are present an additional loss term to account for loss of ions by attachment to these aerosols is added to Eq. (7): $-\beta \mathrm{IN}$, where $\beta$ is the attachment coefficient. If this is the dominating loss term then the steady state solution for the ions become linearly dependent on $Q$. To account for this scenario, or an alternate nucleation mechanism, the detailed case shown in Fig. 3 was also run with a direct correlation between $s$ and $d Q: s(t)=s_{0} d Q(t)$. Here it is assumed that the stable clusters are directly produced before neutralization by recombination happens.

\subsection{Additional nucleation mechanisms occuring simultaneously}

Only sulphuric acid ion induced nucleation is simulated in this study. To investigate how other nucleation mechanisms occuring at the same time influence the results, a third nucleation scheme is examined in which $s(t)=0.5 \times s_{0} \sqrt{d Q(t)}+0.5 \times s_{0}$. In this case the last term is not affected by the ionization and thus simulate that additional nucleation mechanisms (such as homogeneous or ternary nucleation) may happen simultaneously.

These alternate schemes allows us to see how the magnitude of change in AE due to the Forbush decrease changes with varying nucleation. If more elaborate schemes for nucleation of stable clusters are taken into account $s(Q)$ becomes more complex (Lovejoy et al., 2004; Modgil et al., 2005). For this study the simple relations listed above will suffice and the results are described in Sect. 7. 


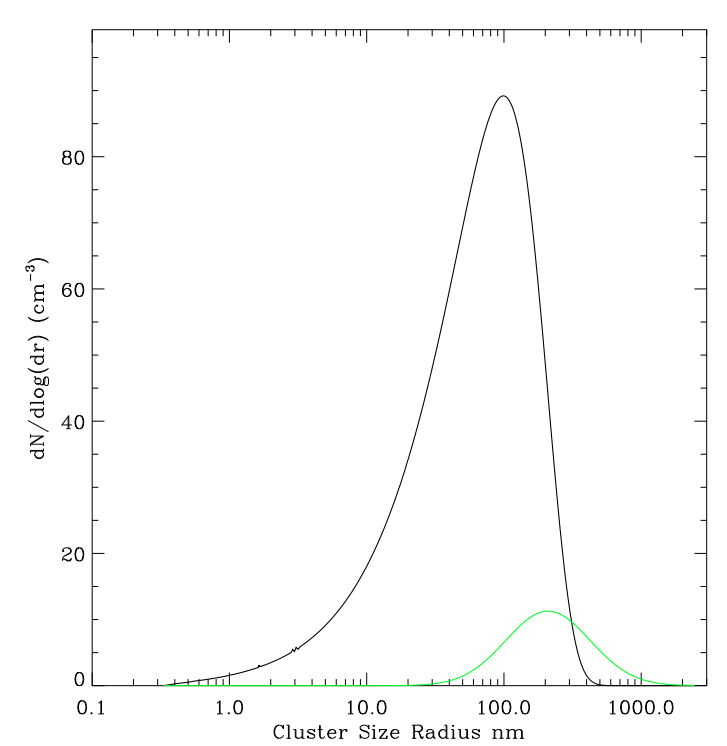

Fig. 2. The resulting aerosol distribution from the single model run with $\kappa=1.5$ days, $P_{\mathrm{H}_{2} \mathrm{SO}_{4}}=20000 \mathrm{~cm}^{-3} \mathrm{~s}^{-1}, s=0.001 \mathrm{~cm}^{-3} \mathrm{~s}^{-1}$ described in Sect. 4. The black line shows the distribution resulting from the nucleated aerosols 15 days before the FD minimum. The green line shows the sea salt accumulation mode. The sea salt coarse mode is not visible.

\section{Output of model from a single run}

Figure 2 shows the resulting size distribution from a single run with $\kappa=1.5$ days, $P_{\mathrm{H}_{2} \mathrm{SO}_{4}}=20000 \mathrm{~cm}^{-3} \mathrm{~s}^{-1}$, $s=0.001 \mathrm{~cm}^{-3} \mathrm{~s}^{-1}$ at 15 days before the FD minimum. The number concentration (excluding sea-salt) is $\sim 90 \mathrm{~cm}^{-3}$ and the mean diameter is $246 \mathrm{~nm}$. This is somewhat higher than the typical accumulation mode as seen in Heintzenberg et al. (2000), but fits well with the $266 \mathrm{~nm}$ given by Seinfeld and Pandis (2006, p. 371, Table 8.3). As can be seen in Table 2 this particular run is one of those with the highest resulting particle diameter.

In Fig. 3 the upper plot is output from the above run and shows the Angstrom exponent (black line) as a function of the 36 days representing the FD (black dashed). The effective radius (red) as well as the number of $\mathrm{H}_{2} \mathrm{SO}_{4}$ particles: $N_{\text {total }}$ (blue solid), $N>3 \mathrm{~nm}$ (blue dashed) and $N>100 \mathrm{~nm}$ (blue point-dashed) is also shown. The two lower plots gives the optical depths at $\lambda=350$ and $450 \mathrm{~nm}$ used to calculate the upper plot.

For this choice of parameters it is observed how the Angstrom exponent decreases by $\approx 2 \%$ to a minimum approximately 3 days after the FD minimum. The explanation is that at the onset of the FD the cluster production, $s$, and hence the number of small particles decreases. Since the loss rate remains constant this causes the total particle number to decrease and a subsequent minimum in $\tau_{350}$ is observed around the time of the FD minimum. A couple of days after the FD minimum the optical depth for $\lambda=350 \mathrm{~nm}$ returns to

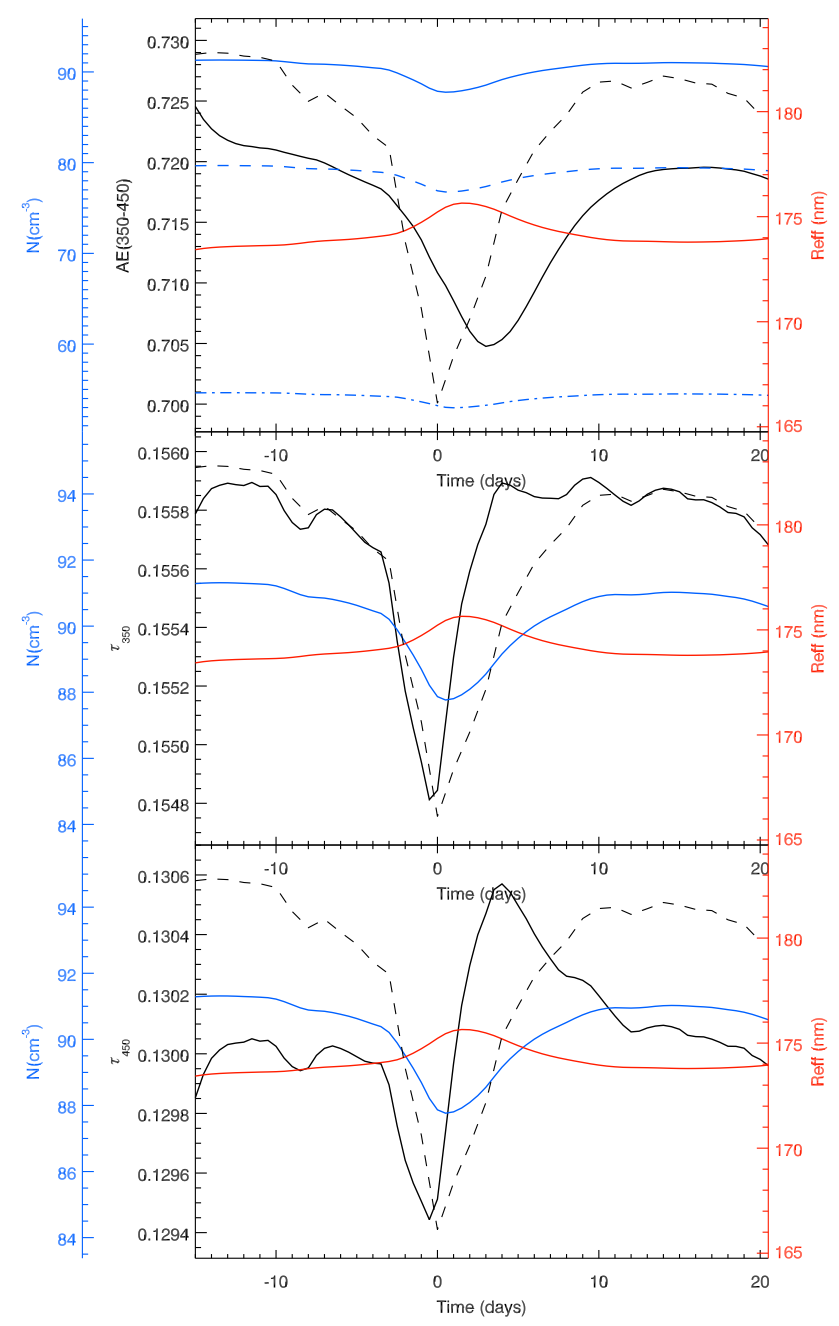

Fig. 3. The upper plot is model output from a single run with $\kappa=1.5$ days, $p=20000 \mathrm{~cm}^{-3} \mathrm{~s}^{-1}, s=0.001 \mathrm{~cm}^{-3} \mathrm{~s}^{-1}$ and shows the Angstrom exponent (black line) over 36 days for the FD (black dashed) as described in Sect. 3. The effective radius (red) and the number of non sea salt aerosols: $N_{\text {total }}$ (blue solid), $N>3 \mathrm{~nm}$ (blue dashed) and $N>100 \mathrm{~nm}$ (blue point-dashed) are also shown. The two lower plots show the optical depths at $\lambda=350 \mathrm{~nm}$ and $450 \mathrm{~nm}$.

its initial value. Note that this happens several days before the particle number returns to its original value. The reason being that as the number of particles go down, the remaining ones increase in size, due to reduced competition for the sulphuric acid. As the particle radius increases, so does the optical thickness. The same pattern is observed for $\lambda=450 \mathrm{~nm}$, however the optical depth increases above its original value, before it relaxes back. This is due to a higher sensitivity to the particle radius, since this wavelength is further away from the effective radius of the particle population $(174 \mathrm{~nm})$. The difference in behaviour for the optical thickness at the two wavelengths show the complex dependence of the AOT on particle number and radius. Furthermore this is the reason 
Table 2. Model overview of the sensitivity study of various optical parameters and sulphuric acid concentrations as function of loss rates, sulphuric acid production rates and cluster production rates as described in Sect. 5. Each box represents a value of $s$ and $P_{\mathrm{H}_{2}} \mathrm{SO}_{4}$. In each box the colors represent the loss values of $\kappa=0.5,1,1.5,2,1000$ days increasing from a value of 0.5 days (bottom) to 1000 days (top). For each loss value the first number gives the base level of the Angstrom exponent defined as the mean of the first 10 days of Angstrom exponent output ( $t=-15$ to -5 days). The second number is the per mille deviation of the largest extremum of days -5 to 20 from the base level. Positive numbers mean an increase in $\mathrm{AE}$ and vice versa. The two following numbers are the mean of the 10 first days of the effective radius in $\mathrm{nm}$ and sulphuric acid concentration in $\mathrm{cm}^{-3}$ (divided by $10^{7}$ ), respectively.

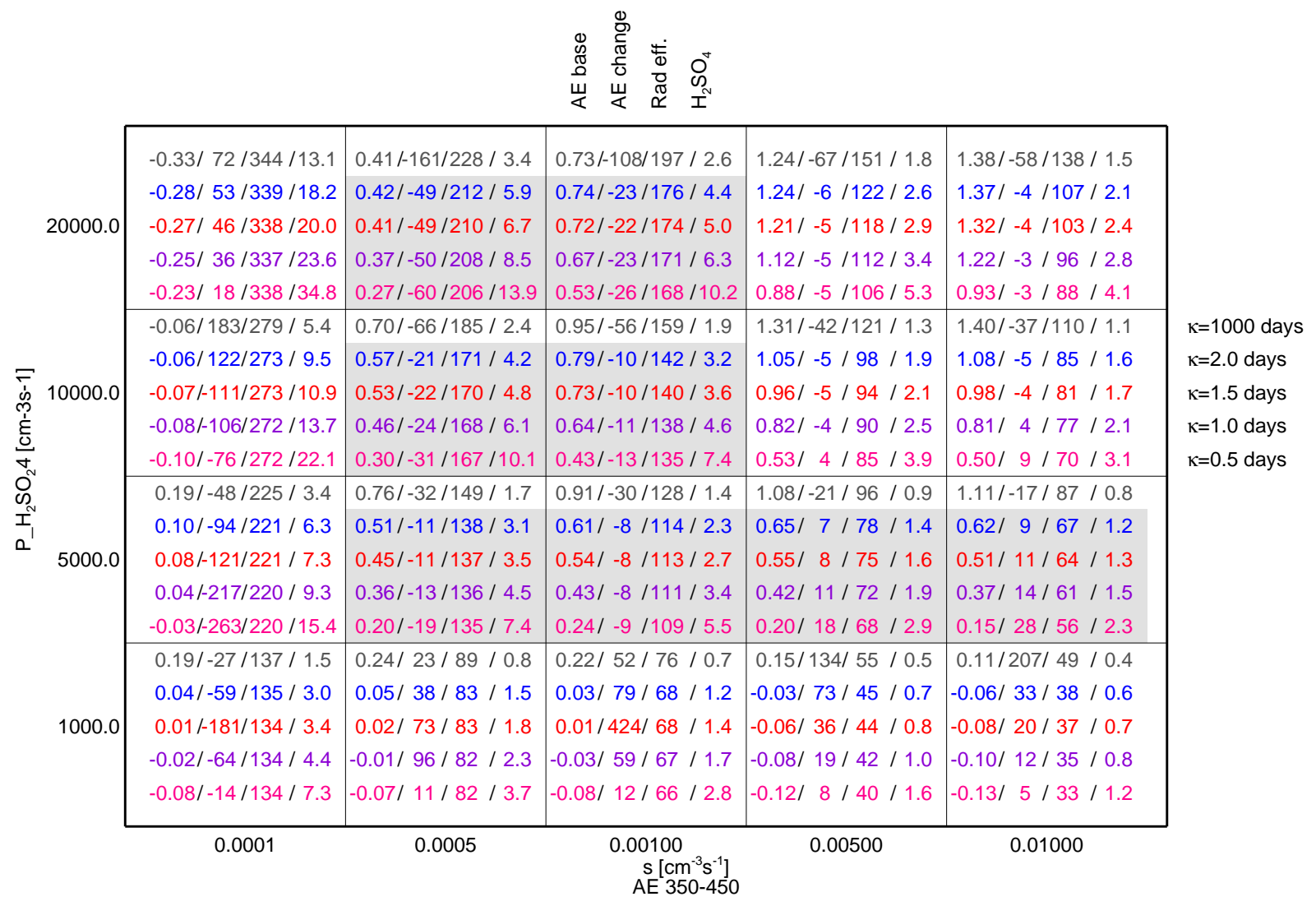

for the observed lag of 3 days in the dip of the AE compared to the dip in the FD. An obvious interpretation of this lag, if seen in observational data, would be to attribute it to the time it takes from the decrease in production of small particles to propagate up to sizes detectable at the employed wavelengths. Our analysis, however, shows that this is not the only possible explanation, but that the increase in radius of the remaining population must also be considered.

\section{Output of model from parameter space}

In Table 2 the whole parameter space is explored. Each box represents a value of $s$ and $P_{\mathrm{H}_{2} \mathrm{SO}_{4}}$. In each box the colors represent the loss values of $\kappa=0.5,1,1.5,2,1000$ days increasing from a value of 0.5 days (bottom) to 1000 days (top). For each loss value the first number gives the base level of the Angstrom exponent defined as the mean of the first 10 days of Angstrom exponent output ( $t=-15$ to -5 days). The second number is then the per mille deviation of the largest extremum of day -5-20 from the base level, with positive numbers meaning an increase in $\mathrm{AE}$ and vice versa. The two following numbers are the mean of the 10 first days of the effective radius in $\mathrm{nm}$ and sulphuric acid concentration in $\mathrm{cm}^{-3}$ (divided by $10^{7}$ ), respectively.

Three types of responses are behind the different percentage responses. The standard case is the one outlined in Sect. 4 where a small dip appears in the Angstrom exponent. However, in a few cases the choice of input parameters gives a peak in the Angstrom exponent indicating that a decrease in small particle population may also lead to increases in AE. This happens when the effective radius gets below a certain point around $80 \mathrm{~nm}$ (depending somewhat on $s$ and $P_{\mathrm{H}_{2} \mathrm{SO}_{4}}$ ), far away from the probing wavelengths of 350 and $450 \mathrm{~nm}$. A switch in sensitivity then seems to happen causing the low wavelength to be more sensitive to the change in effective radius than the high wavelength, as opposed to what was seen in the single run of Sect. 4. Since 
the AOT at $350 \mathrm{~nm}$ then increases the most as the radius of the particle population grows, this causes an increase in the $\mathrm{AE}$. The third response is the case where no mixing occurs ( $\kappa=1000$ days). Here very large changes in the AE is typically observed. These rather large percentage changes are more a result of an unstable initial precondition run than a real decrease in Angstrom exponent caused by the modulation of cluster production. When there is no loss for the particles, steady state is never reached and therefore the effective radius continues to grow, causing a decrease of the $\mathrm{AE}$, throughout these runs. Since the AE is then much lower after the FD, simply because of this overall growth of the population, artificially high changes appear. The runs with $\kappa=1000$ days should generally be regarded with care.

For a constant loss rate and cluster production an increase in $P_{\mathrm{H}_{2} \mathrm{SO}_{4}}$ in general leads to higher Angstrom exponent base level. This is explained by the larger increase in available condensable gas enabling better growth of the smaller particles. This will cause the optical depth to increase for $350 \mathrm{~nm}$ and hence the Angstrom exponent to increase. Note also that the effective radius increases with $P_{\mathrm{H}_{2} \mathrm{SO}_{4}}$, in all cases. However, if the effective radius gets too high then an increase in $P_{\mathrm{H}_{2} \mathrm{SO}_{4}}$ can cause a decrease in $\mathrm{AE}$ level since the sensitivity of the AOT at 450 starts to increase. Similarly, for a constant sulphuric acid and cluster production an increase in $\kappa$ leads to higher Angstrom exponent base level. This is natural since higher half lives results in fewer small particles being removed.

And again, for a constant loss rate and sulphuric acid production an increase in $s$ in general leads to higher Angstrom exponent base level. This is explained by an increase in the number concentration of smaller particle, causing the AOT at $350 \mathrm{~nm}$ to increase at a higher rate than at $450 \mathrm{~nm}$. Additionally a high $s$ leads to a decrease in effective radius, due to an increased competition for the sulphuric acid. In a few cases this actually causes the AE to decrease as $s$ increases (for instance for $P_{\mathrm{H}_{2} \mathrm{SO}_{4}}=1000.0 \mathrm{~cm}^{-3} \mathrm{~s}^{-1}$ and $s$ going from 0.00500 to $0.01000 \mathrm{~cm}^{-3} \mathrm{~s}^{-1}$.

As can be observed the baseline values vary from small negative numbers to a maximum around 1.4 in Angstrom exponent. In Sano (2004) the average Angstrom exponent over the ocean is about 0.5. In Kazil et al. (2006) and Weber et al. (2001) the sulphuric acid concentration over the oceans was found based on both modelling and measurements. Here values of sulphuric acid concentration in the lower troposphere over the ocean was about $10^{7} \mathrm{~cm}^{-3}$. If these values are compared with our results this can be used to restrict the solution space of sulphuric acid production and cluster production to the region $0.0005 \mathrm{~cm}^{-3} \mathrm{~s}^{-1} \leq \mathrm{s} \leq 0.001 \mathrm{~cm}^{-3} \mathrm{~s}^{-1}$ and $P_{\mathrm{H}_{2} \mathrm{SO}_{4}} \geq 5000 \mathrm{~cm}^{-3} \mathrm{~s}^{-1}$ and the region $0.005 \mathrm{~cm}^{-3} \mathrm{~s}^{-1} \leq \mathrm{s}$ $\leq 0.01 \mathrm{~cm}^{-3} \mathrm{~s}^{-1}$ with $P_{\mathrm{H}_{2} \mathrm{SO}_{4}}=5000 \mathrm{~cm}^{-3} \mathrm{~s}^{-1}$. This region is shaded in grey in the table and indicates the most probable optical response in the marine troposphere to Forbush decreases under the assumption of a square root dependency of the cluster formation rate to the ion production. As can be observed the expected average change in percentage of the Angstrom exponent is of the order of -6 to $3 \%$ in the shaded region, compared to the initial $10 \%$ modulation in ionization.

The AE change is a function of the relative change in the two optical depths. These in turn depend strongly on particle size and number. Ignoring negative AE base levels and those very close to 0 there does seem to be some trends in the AE change. When the effective radius increase so does the AE change (for constant half-lifes). This is seen clearly, for instance, for $P_{\mathrm{H}_{2} \mathrm{SO}_{4}}$ going from $5000 \mathrm{~cm}^{-3} \mathrm{~s}^{-1}$ to $20000 \mathrm{~cm}^{-3} \mathrm{~s}^{-1}$, for all half-lives. When $R_{\text {eff }}$ goes below a certain limit, around $80 \mathrm{~nm}$ as noted above, the change switches from negative to positive. An example of this is for $P_{\mathrm{H}_{2} \mathrm{SO}_{4}}=5000 \mathrm{~cm}^{-3} \mathrm{~s}^{-1}$ and $\mathrm{s}$ going from 0.001 to $0.005 \mathrm{~cm}^{-3} \mathrm{~s}^{-1}$. These results indicate that wavelengths close to the effective radius of the particle population are best suited for making observations of the response in AE to Forbush decreases.

Finally, a similar analysis was performed for the wavelength pair of $550-900 \mathrm{~nm}$. The reason for selecting this wavelength pair is that the MODIS instrument (Platnick et al., 2003) as well as AERONET measures these or similar wavelength pairs. However, this wavelength pair probes sizes of the particle distribution where almost no particles remain. Therefore smaller decreases or increases (of the order of maximum 1\%) in the Angstrom exponent are observed. This will be elaborated on in Sect. 8 where the model results are compared with observations.

\section{Modifying the sea salt distribution}

The sea salt modes used in this study are described in Sect. 2.3. In this section we examine the sensitivity of our results to changes in these modes.

Natural sea salt can have a wide range of sizes (Pierce and Adams, 2006), from a few nanometer (Clarke et al., 2006) and up to micrometers (O'Dowd et al., 1999). Due to limitations in the available data for refractive indices we have limited our sensitivity study to variations in the two modes provided by OPAC. Firstly a run, based on the case in Fig. 3, was made where all sea salt was removed, to gauge the overall contribution of the sea salt to the optical parameters. The AE increased from 0.72 to 1.14 which is well in line with the understanding that smaller particles yield higher AE. The optical thicknesses at $350 \mathrm{~nm}$ and $450 \mathrm{~nm}$ dropped by 0.045 and 0.046 , respectively. The base values were 0.156 and 0.130 , meaning that the sea salt contributes $29 \%$ to the optical thickness at $350 \mathrm{~nm}$ and $36 \%$ at $450 \mathrm{~nm}$.

Figure 4 shows the output of 9 different runs, again based on the case in Fig. 3, where the number density of the two sea salt modes have been varied. Both modes have been run with its standard value $(s t)$ provided by OPAC, a $50 \%$ decrease (d50), and a 50\% increase (i50), producing the 9 plots shown in the figure, such that $d 50 i 50$ means that the accumulation 


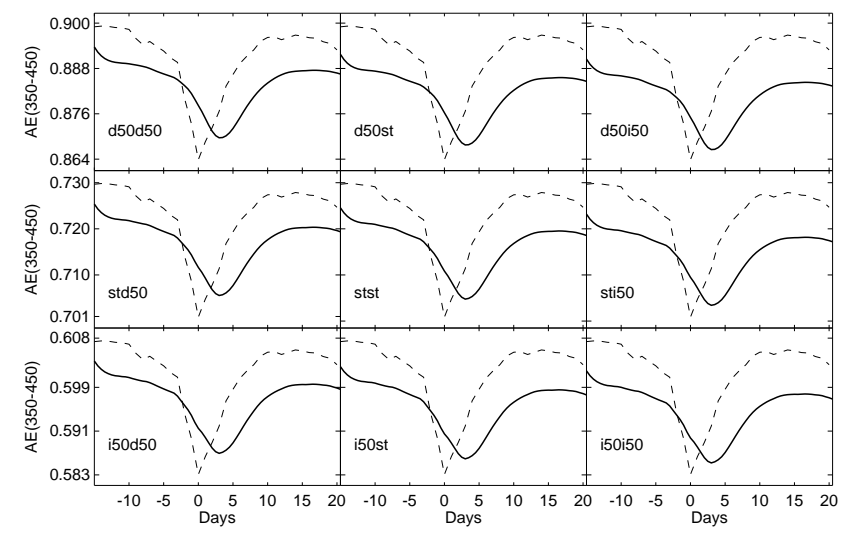

Fig. 4. Variations of the sea salt distribution. This figure shows the output of 9 runs, based on the run described in Sect. 4, but with different levels of sea salt. $d 50$ refers to a $50 \%$ decrease in a mode, $s t$ to the standard value, and $i 50$ to a $50 \%$ increase. The accumulation mode is listed first and the coarse mode last. The full line shows the $\mathrm{AE}$, the dashed line is the FD profile as described in Sect. 3.

mode has been decreased by $50 \%$ and the coarse mode increased similarly. The strongest response in the AE comes from changes in the accumulation mode, which is to be expected since the median size of this mode $(209 \mathrm{~nm})$ is much closer to the wavelengths used to find the $\mathrm{AE}(350 \mathrm{~nm}$ and $450 \mathrm{~nm})$ compared with the coarse mode $(1.75 \mu \mathrm{m})$. Changing the accumulation mode of sea salt by $50 \%$ in either direction shifts the baseline of the AE by about $20 \%$. Similar changes in the coarse mode only yields very small changes in the $\mathrm{AE}$.

Interestingly the dip in $\mathrm{AE}$ due to the Forbush decrease seems to be more or less undisturbed by the changes in sea salt, changing from $2.2 \%$ in the $d 50 d 50$ case to $2.3 \%$ for i50i50. For the run with no sea salt the dip is also $2.2 \%$. To investigate this further a run was made where the amount of sea salt was increased to an amount corresponding to a high wind speed of $18 \mathrm{~m} \mathrm{~s}^{-1}$. This was done using the empirical law found by Mulcahy et al. (2008), stating that the marine aerosol optical thickness scales with the square of the windspeed. The AE thus decreased to 0.28 and the dip increased to $2.7 \%$. These runs show that the amount of sea salt mostly serves as a sort of baseline change to the optical thickness and thus AE, whereas the dip in the AE is not affected greatly. The caveat here is that a change in sea salt would normally be accompanied by a change in loss rate for the nucleated particles, which is not modeled here. Instead effects of changing loss rates are looked at separately in Sect. 5.

\section{Modifying cluster formation rate}

The responses shown in the previous section are dependent on how ionization influences cluster formation. Based on results from Svensmark et al. (2007) a square root dependency

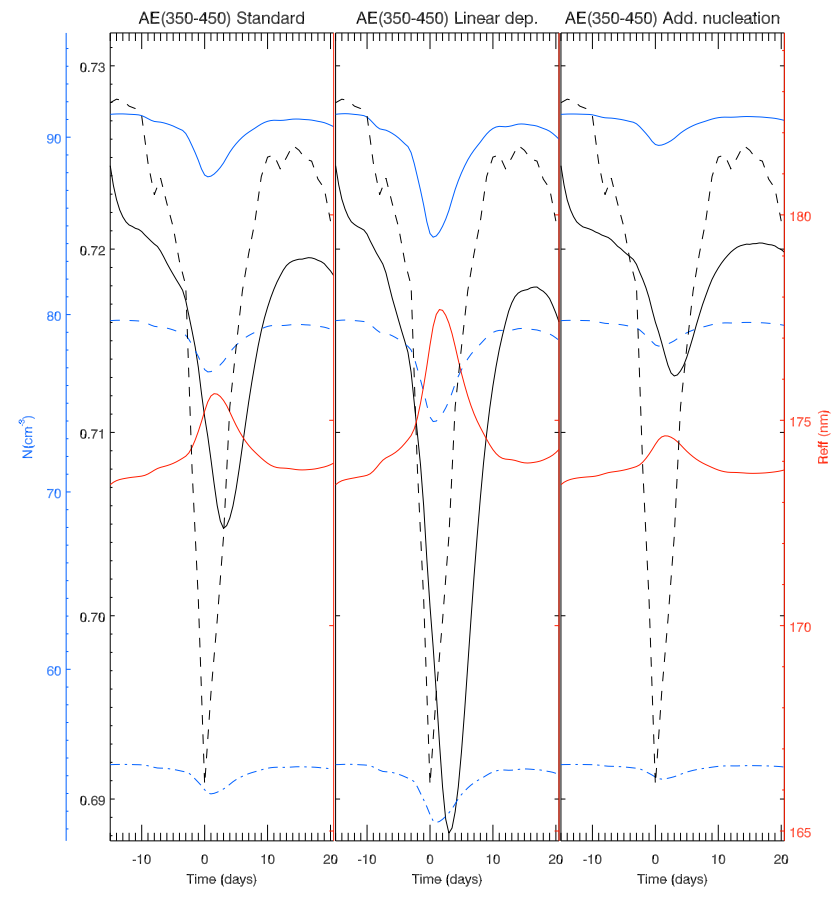

Fig. 5. Alternate nucleation schemes as described in Sect. 7. The figure is based on Fig. 3 with: (left) standard case, (middle) linear cluster formation dependency (right) $50 \%$ alternative nucleation. The black solid line represents the AE, the black dashed line is the FD profile as described in Sect. 3. The effective radius (red) and the number of non sea salt aerosols: $N_{\text {total }}$ (blue solid), $N>3 \mathrm{~nm}$ (blue dashed) and $N>100 \mathrm{~nm}$ (blue point-dashed) are also shown.

of the cluster formation rate was assumed (see Sect. 3). This however is still an open question and it is therefore natural to investigate other mechanisms. This section indicates how other mechanisms may influence the results of the two previous sections.

Figure 5 shows the result from the single run (see Sect. 4) with the two alternate nucleation schemes as presented in Sect. 3. The left plot is identical to upper plot in Fig. 3. In the middle plot a linear dependency of the cluster formation rate to the ionization is examined. Here it can be seen that removing the square root dependency increases the dip in Angstrom exponent by about $50 \%$ due to the larger variations in cluster formation rate. In the right plot the cluster formation is again assumed to have a square root dependency and additionally $50 \%$ of the perturbation by the FD is now removed by adding a constant term to the time varying cluster production. Here the response goes down with about 50\%. This means that the effect of Forbush decreases is dependent on both how ionization affect nucleation as well as the ratio of effectiveness of the different competing nucleation mechanisms in the marine troposphere. 

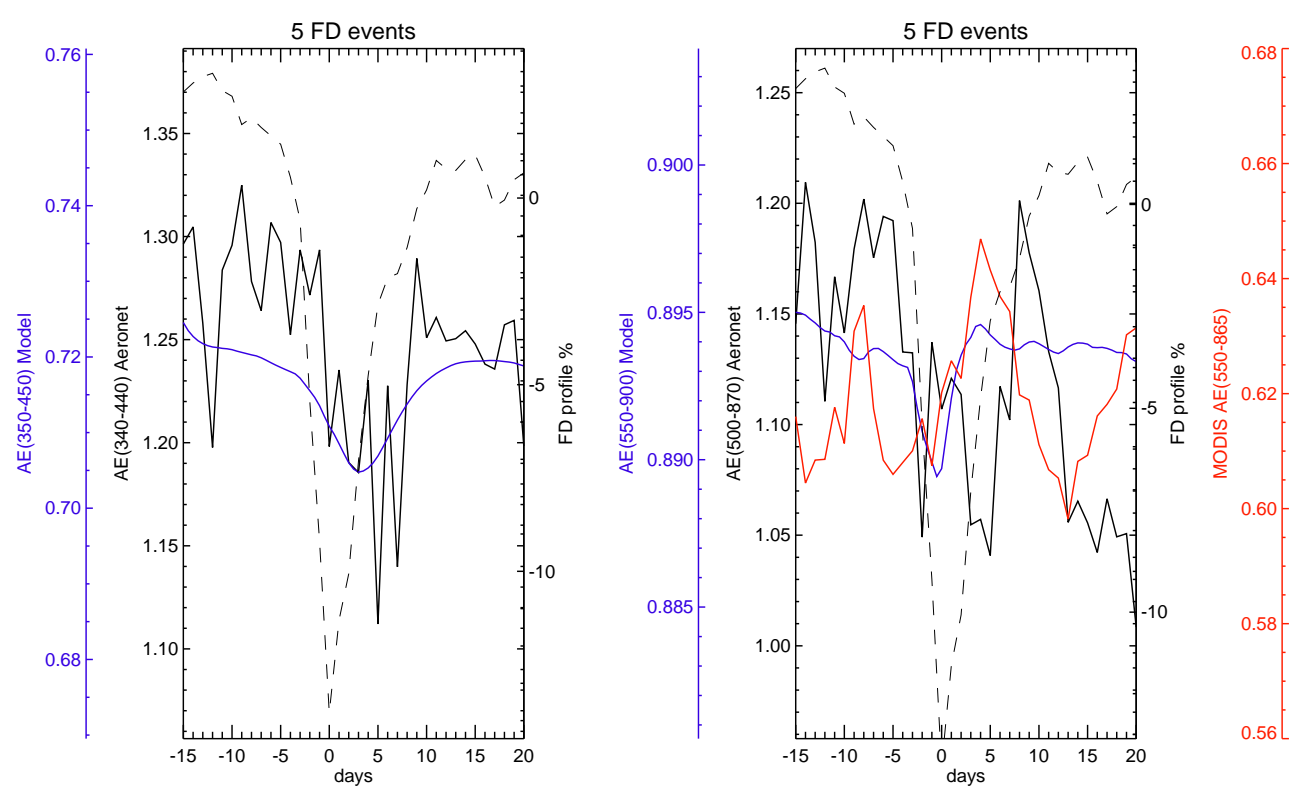

Fig. 6. Angstrom exponents from model and observations (MODIS and AERONET) for the short wavelength pair (left) and long wavelength pair (right). The solid blue curve is the AE from the model, the solid black line is the AE from AERONET, the dashed black line is the FD profile in \%-deviation, the solid red line is the MODIS AE.

\section{Comparison with observations}

Svensmark et al. (2009) made an epoch analysis of AERONET data from 5 major FD events. Angstrom exponent data $(340-440 \mathrm{~nm})$ from approximately 40 stations (stations with more than 20 measurements a day) were superposed and averaged over the 5 events (31 October 2003, 13 September 2005, 19 January 2005, 16 July 2000, 12 April 2001). In this section we compare those results with the model runs. Additionally we investigate the wavelength pair $550,900 \mathrm{~nm}$ which can be compared with both AERONET and MODIS data.

The left of Fig. 6 shows a comparison of Angstrom exponents for the short wavelength pair from the model (350, $450 \mathrm{~nm}$ ) and from the average of the 5 FDs from AERONET $(340,440 \mathrm{~nm})$. The right of Fig. 6 shows the wavelength pairs AERONET $(500,870 \mathrm{~nm})$, MODIS $(550,865 \mathrm{~nm})$, and Model $(550,900 \mathrm{~nm})$. The dashed line is the average of the FD signal over the events listed above, plotted as percentage deviation from the mean of day -15 to day -1 . First, it is observed that the values for AERONET are higher than the values for both the model and MODIS. This is because the land based AERONET stations have more small mode fraction particles due to aerosols from e.g. pollution, dust, and biomass burnings ${ }^{1}$. Even though the AERONET stations are mainly placed on land we have included this data set anyway, since it is the only one available at the low wavelength pair

\footnotetext{
${ }^{1}$ Note that the FD events are not identical to the ones used in the model but that the average of the peak is more or less the same. For the purpose of this exercise this is more than adequate.
}

and since a response to the FDs was actually found in the previous study by Svensmark et al. (2009).

The left figure shows a slight significant signal for the short wavelength pair for AERONET where a decrease in the Angstrom exponent is observed a couple of days after the FD minimum for the 5 events. However, for the longer wavelength pairs in the right figure both for MODIS and AERONET no significant signal seem to be present. Since we are comparing an ocean based model with land based observations no direct comparison can be made but we can however point to some trends. There is a systematic decrease of a factor of approximately 2-4 in signal for going from the small wavelength pair to the larger in our model. Assuming that the weak signal observed in Svensmark et al. (2009) is real then the signal from the long wavelength pairs could be lowered into the climatic noise of the Angstrom exponent observations. If a linear dependency of the cluster formation rate is assumed this effect would even be more pronounced (see Sect. 7). This seems to be confirmed by the left of Fig. 6 although more observations would be needed to examine this in more detail. Therefore if an ion induced mechanism is working as in our model, it is expected that observations based on the shorter wavelength pair would be the most favourable for seeing the FD effect. 


\section{Summary}

Under the assumption that ion induced nucleation play a role in the marine troposphere, a simple aerosol growth model in combination with a Mie scattering code and an optical properties program was used to model Angstrom exponents over the tropospheric ocean for two wavelength pairs (350, $450 \mathrm{~nm}$ and 550, $900 \mathrm{~nm}$ ) during a Forbush decrease by modulating the nucleation rate over time by the ionization profile from the Forbush decrease. The marine environment was modeled by a fixed-in-time bimodal sea salt distribution and a variable sulphuric acid aerosol distribution. A large parameter space was explored by altering nucleation mode cluster production rates, sulphuric acid production, loss rates, as well as exploring alternative nucleation mechanism. Distinct but highly varying responses in the optical properties were found by changing the initial parameter settings. For the short wavelength pair $(350,450 \mathrm{~nm})$ changes in the Angstrom exponent of about -6 to $3 \%$ was found for realistic settings of the Angstrom exponent base level values and sulphuric acid concentration as compared to the marine troposphere. For the longer wavelength pair $(550,900 \mathrm{~nm})$ the changes were generally a factor of $2-4$ lower. This seems to match with observations from AERONET and MODIS where an epoch analysis of 5 major FD events reveal a slight significant signal in the wavelength pair $(340,440 \mathrm{~nm})$ and not in the longer wavelength pair $(550,900 \mathrm{~nm})$.

The study encourages more global observations of Angstrom exponents at smaller wavelength pairs and improving the signal to noise ratio further. This may help to improve the understanding of the importance of ion induced nucleation and of how secondary aerosol distributions affect the marine optical properties. Future work related to atmospheric Forbush Decrease responses could be done with more advanced GCM models and should focus on implementing a dynamic sea salt distribution, cloud processing, and investigating other nucleation schemes and growth rates further.

Acknowledgements. Martin Enghoff would like to thank the Carlsberg Foundation for funding this work.

Edited by: M. Kulmala

\section{References}

Arnold, F.: Multi-ion complexes in the stratosphere - Implications for trace gases and aerosol, Nature, 284, 610-611, 1980.

Cane, H.: Coronal mass ejections and forbush decreases, Space Sci. Rev., 93, 55-77, 2000.

Clarke, A. D. and Kapustin, V. N.: A pacific aerosol survey. part I: A decade of data on particle production, transport, evolution, and mixing in the troposphere, J. Atmos. Sci., 52, 363-382, 2002.

Clarke, A., Owens, S., and Zhou, J.: An ultrafine sea-salt flux from breaking waves: Implications for cloud condensation nuclei in the remote marine atmosphere, J. Geophys. Res.-Atmos., 111, D06202, doi:10.1029/2005JD006565, 2006.

Eck, T. F., Holben, B. N., Reid, J. S., Dubovik, O., Smirnov, A., O'Neill, N. T., Slutsker, I., and Kinne, S.: Wavelength depen- dence of the optical depth of biomass burning, urban, and desert dust aerosols, J. Geophys. Res., 104, 31333-31349, 1999

Eichkorn, S., Wilhelm, S., Aufmhoff, H., Wohlfrom, K. H., and Arnold, F.: Cosmic ray-induced aerosol-formation: First observational evidence from aircraft-based ion mass spectrometer measurements in the upper troposphere, Geophys. Res. Lett., 29, 43-1, 2002.

Enghoff, M. B., Pedersen, J. O. P., Bondo, T., Johnson, M. S., Paling, S., and Svensmark, H.: Evidence for the Role of Ions in Aerosol Nucleation, J. Phys. Chem. A, 112, 10305-10309, doi:10.1021/jp806852d, 2008.

Forbush, S. E.: On the Effects in Cosmic-Ray Intensity Observed During the Recent Magnetic Storm, Physical Review, 51, 11081109, doi:10.1103/PhysRev.51.1108.3, 1937.

Harrison, R. G. and Stephenson, D. B.: Empirical evidence for a nonlinear effect of galactic cosmic rays on clouds, Proceedings of the Royal Society A, 462, 1221-1233, 2006.

Heintzenberg, J., Covert, D. C., and Van Dingenen, R.: Size distribution and chemical composition of marine aerosols: a compilation and review, Tellus, 52B, 1104-1122, 2000.

Hess, M., Koepke, P., and Schult, I.: Optical Properties of Aerosols and Clouds: The Software Package OPAC., B. Am. Meteorol. Soc., 79, 831-844, doi:10.1175/1520-0477(1998)079, 1998.

Hirsikko, A., Yli-Juuti, T., Neiminen, T., Vartiainen, E., Laakso, L., Hussein, T., and Kulmala, M.: Indoor and outdoor air ions and aerosol particles in the urban atmosphere of Helsinki: characteristics, sources and formation, Boreal Environ. Res., 12, 295-310, 2007.

Holben, B., Eck, T., Slutsker, I., Tanré, D., Buis, J., Setzer, A., Vermote, E., Reagan, J., Kaufman, Y., Nakajima, T., Lavenu, F., Jankowiak, I. and Smirnov, A.: AERONET - A federated instrument network and data archive for aerosol characterization, Rem. Sens. Environ, 66, 1-16, 1998.

Kazil, J., Lovejoy, E. R., Barth, M. C., and O'Brien, K.: Aerosol nucleation over oceans and the role of galactic cosmic rays, Atmos. Chem. Phys., 6, 4905-4924, 2006, http://www.atmos-chem-phys.net/6/4905/2006/.

Kim, T. O., Adachi, M., Okuyama, K., and Seinfeld, J. H.: Experimental Measurement of Competitive Ion-Induced and Binary Homogeneous Nucelation in $\mathrm{SO}_{2} / \mathrm{H}_{2} \mathrm{O} / \mathrm{N}_{2}$ Mixtures, Aerosol Sci. Tech., 26, 527-543, 1997.

Kniveton, D. R.: Precipitation, cloud cover and Forbush decreases in galactic cosmic rays, J. Atmos. Terr. Phys., 66, 1135-1142, 2004.

Kristjánsson, J. E., Stjern, C. W., Stordal, F., Fjraa, A. M., Myhre, G., and Jónasson, K.: Cosmic rays, cloud condensation nuclei and clouds - a reassessment using MODIS data, Atmos. Chem. Phys., 8, 7373-7387, 2008,

http://www.atmos-chem-phys.net/8/7373/2008/.

Kuang, C., McMurry, P. H., and McCormick, A. V.: Determination of cloud condensation nuclei production from measured new particle formation events, Geophys. Res. Lett., 36(9), L09822, doi:10.1029/2009GL037584, 2009.

Kulmala, M., Riipinen, I., Sipilä, M., Manninen, H. E., Petäjä, T., Junninen, H., Dal Maso, M., Mordas, G., Mirme, A., Vana, M., Hirsikko, A., Laakso, L., Harrison, R. M., Hanson, I., Leung, C., Lehtinen, K. E. J., and Kerminen, V.-M.: Toward Direct Measurement of Atmospheric Nucleation, Science, 318, 89-92, doi:10.1126/science.1144124, 2007. 
Kulmala, M., Riipinen, I., Nieminen, T., Hulkkonen, M., Sogacheva, L., Manninen, H. E., Paasonen, P., Petäjä, T., Dal Maso, M., Aalto, P. P., Viljanen, A., Usoskin, I., Vainio, R., Mirme, S., Mirme, A., Minikin, A., Petzold, A., Hõrrak, U., Plaß-Dülmer, C., Birmili, W., and Kerminen, V.-M.: Atmospheric data over a solar cycle: no connection between galactic cosmic rays and new particle formation, Atmos. Chem. Phys., 10, 1885-1898, 2010, http://www.atmos-chem-phys.net/10/1885/2010/.

Laakso, L., Mäkelä, J. M., Pirjola, L., and Kulmala, M.: Model studies on ion-induced nucleation in the atmosphere, J. Geophys. Res. Atmos., 107, 4427-4445, doi:10.1029/2002JD002140, 2002.

Laakso, L., Gagné, S., Petäjä, T., Hirsikko, A., Aalto, P. P., Kulmala, M., and Kerminen, V.-M.: Detecting charging state of ultra-fine particles: instrumental development and ambient measurements, Atmos. Chem. Phys., 7, 1333-1345, 2007,

http://www.atmos-chem-phys.net/7/1333/2007/.

Laaksonen, A., Vesala, T., Kulmala, M., Winkler, P. M., and Wagner, P. E.: Commentary on cloud modelling and the mass accommodation coefficient of water, Atmos. Chem. Phys., 5, 461-464, 2005, http://www.atmos-chem-phys.net/5/461/2005/.

Lee, S.-H., Reeves, J. M., Wilson, J. C., Hunton, D. E., Viggiano, A. A., Miller, T. M., Ballenthin, J. O., and Lait, L. R.: Particle Formation by Ion Nucleation in the Upper Troposphere and Lower Stratosphere, Science, 301, 1886-1889, doi:10.1126/science.1087236, 2003.

Lehtinen, K. E. J. and Kulmala, M.: A model for particle formation and growth in the atmosphere with molecular resolution in size, Atmos. Chem. Phys., 3, 251-257, 2003,

http://www.atmos-chem-phys.net/3/251/2003/.

Lovejoy, E. R., Curtius, J., and Froyd, K. D.: Atmospheric ioninduced nucleation of sulfuric acid and water, J. Geophys. Res. Atmos., 109, 1-11, doi:10.1029/2003JD004460, 2004.

Marsh, N. and Svensmark, H.: Galactic cosmic ray and El NiñoSouthern Oscillation trends in International Satellite Cloud Climatology Project D2 low-cloud properties, J. Geophys. Res. Atmos., 108, 4195-4205, doi:10.1029/2001JD001264, 2003.

Modgil, M., Kumar, S., Tripathi, S., and Lovejoy, E.: A parameterization of ion-induced nucleation of sulphuric acid and water for atmospheric conditions, J. Geophys. Res. Atmos., 110(19), D19205, doi:10.1029/2004JD005475, 2005.

Mulcahy, J. P., O'Dowd, C. D., Jennings, S. G., and Ceburnis, D.: Significant enhancement of aerosol optical depth in marine air under high wind conditions, Geophys. Res. Lett., 35, L16810, doi:10.1029/2008GL034303, 2008.

O’Dowd, C., McFiggans, G., Creasey, D. J., Pirjola, L., Hoell, C., Smith, M. H., Allan, B. J., Plane, J. M. C., Heard, D. E., Lee, J. D., Pilling, M. J., and Kulmala, M.: On the photochemical production of new particles in the coastal boundary layer, Geophys. Res. Lett., 26, 1707-1710, doi:10.1029/1999GL900335, 1999.

Pierce, J. and Adams, P.: Global evaluation of CCN formation by direct emission of sea salt and growth of ultrafine sea salt, J. Geophys. Res. Atmos., 111, D06203, doi:10.1029/2005JD006186, 2006.

Pierce, J. R. and Adams, P. J.: Efficiency of cloud condensation nuclei formation from ultrafine particles, Atmos. Chem. Phys., 7, 1367-1379, 2007,

http://www.atmos-chem-phys.net/7/1367/2007/.

Pierce, J. R. and Adams, P. J.: Can cosmic rays affect cloud conden- sation nuclei by altering new particle formation rates?, Geophys. Res. Lett., 36, L09820, doi:10.1029/2009GL037946, 2009.

Platnick, S., King, M. D., Ackerman, S. A., Menzel, W. P., Baum, B. A., Riedi, J. C., and Frey, R. A.: The MODIS cloud products: algorithms and examples from terra, IEEE Transactions on Geoscience and Remote Sensing, 41, 459-473, doi:10.1109/TGRS.2002.808301, 2003.

Pudovkin, M. I. and Veretenenko, S. V.: Cloudiness decreases associated with Forbush decreases of galactic cosmic rays., J. Atmos. Terr. Phy., 57, 1349-1355, 1995.

Reid, J. S., Eck, T. F., Christopher, S. A., Hobbs, P. V., and Holben, B. N.: Use of the Angstrom exponent to estimate the variability of optical and physical properties of aging smoke particles in Brazil, J. Geophys. Res., 104, 27473-27489, 1999.

Sano, I.: Optical thickness and Angstrom exponent of aerosols over the land and ocean from space-borne polarimetric data, Adv. Space Res., 34, 833-837, 2004.

Schuster, G. L., Dubovik, O., and Holben, B. N.: Angstrom exponent and bimodal aerosol size distributions, J. Geophys. Res. Atmos., 111, 1-14, doi:10.1029/2005JD006328, 2006.

Seinfeld, J. and Pandis, S.: Atmospheric Chemsitry and Physics : From Air Pollution to Climate Change, Wiley, 2 edn., 2006.

Sloan, T. and Wolfendale, A. W.: Testing the proposed causal link between cosmic rays and cloud cover, Environ. Res. Lett., 3, 17, doi:10.1088/1748-9326/3/2/024001, 2008.

Svensmark, H., Pedersen, J. O. P., Marsh, N. D., Enghoff, M. B., and Uggerhøj, U. I.: Experimental evidence for the role of ions in particle nucleation under atmospheric conditions, P. Roy. Soc. A, 463, 385-396, doi:10.1098/rspa.2006.1773, 2007.

Svensmark, H., Bondo, T., and Svensmark, J.: Cosmic ray decreases affect atmospheric aerosols and clouds, Geophys. Res. Lett., 36, L15101, doi:10.1029/2009GL038429, 2009.

Tinsley, B. A.: The global atmospheric electric circuit and its effects on cloud microphysics, Rep. Prog. Phys., 71, 066801, doi:10.1088/0034-4885/71/6/066801, 2008.

Todd, M. C. and Kniveton, D. R.: Short-term variability in satellitederived cloud cover and galactic cosmic rays: an update, J. Atmos. Terr. Phys., 66, 1205-1211, 2004.

Usoskin, I. G., Gladysheva, O. G., and Kovaltsov, G. A.: Cosmic ray-induced ionization in the atmosphere: spatial and temporal changes, J. Atmos. Sol.-Terr. Phys., 66, 1791-1796, doi:10.1016/j.jastp.2004.07.037, 2004.

Weber, R. J., Chen, G., Davis, D. D., Mauldin III, R. L., Tanner, D. J., Eisele, F. L., Clarke, A. D., Thornton, D. C., and Bandy, A. R.: Measurements of enhanced $\mathrm{H}_{2} \mathrm{SO}_{4}$ and 3-4 nm particles near a frontal cloud during the First Aerosol Characterization Experiment (ACE 1), J. Geophys. Res., 106, 24107-24117, doi:10.1029/2000JD000109, 2001.

Winkler, P. M., Steiner, G., Vrtala, A., Vehkamaki, H., Noppel, M., Lehtinen, K. E. J., Reischl, G. P., Wagner, P. E., and Kulmala, M.: Heterogeneous nucleation experiments bridging the scale from molecular ion clusters to nanoparticles, Science, 319 , 1374-1377, doi:10.1126/science.1149034, 2008.

Wolf, S.: Mie Scattering by Ensembles of Particles with Very Large Size Parameters, Comput. Phys. Commun., 162, 113-123, 2004.

Yu, F.: From molecular clusters to nanoparticles: second-generation ion-mediated nucleation model, Atmos. Chem. Phys., 6, 51935211, 2006, http://www.atmos-chem-phys.net/6/5193/2006/. 